\title{
CONTRATAÇÃO DE PESSOAS COM DEFICIÊNCIA EM PEQUENAS EMPRESAS: UM ESTUDO EM DEZ EMPRESAS MINEIRAS
}

\section{WHY SMALL COMPANIES HIRE PEOPLE WITH DISABILITIES? A STUDY WITH TEN COMPANIES FROM MINAS GERAIS}

\author{
Liliam Medeiros da Silva \\ Universidade Federal de São João del Rei -UFSJ - MG \\ liliamedeirossilva@gmail.com \\ Maria Nivalda de Carvalho-Freitas \\ Universidade Federal de São João del Rei -UFSJ - MG \\ nivalda@ufsj.edu.br \\ Raissa Pedrosa Gomes Tette \\ Universidade Federal de São João del Rei -UFSJ - MG) \\ raissatette@yahoo.com.br
}

Submissão: 20/01/2020 Aprovação: 17/08/2021

\section{RESUMO}

Estudos recentes revelam a baixa receptividade por parte das empresas com relação à prática da inclusão de pessoas com deficiência. No entanto, pesquisa realizada pela Federação Nacional das Associação de Pais e Amigos dos Excepcionais (APAEs), revela que 97,9\% das empresas mineiras que contratavam pessoas com deficiência oriundas dessa instituição têm menos de 100 trabalhadores. O objetivo deste estudo foi compreender os motivos pelos quais gestores de empresas mineiras compostas por um número inferior a 100 funcionários estão contratando pessoas com deficiência, visto que não possuem obrigação legal. Participaram da pesquisa dez empregadores de micro e pequenas empresas (MPEs) de duas mesorregiões do estado de Minas Gerais. Foram adotados métodos qualitativos, com dados coletados em entrevistas e submetidos à análise de conteúdo. Concluiu-se que prevaleceram a Normalidade e a Concepção de Inclusão como Matrizes de Interpretação da deficiência entre os gestores. Contratam-se pessoas com deficiência por dois motivos principais: conhecer a pessoa previamente e indicação e/ou influência da APAE ou outra instituição. Prevalece nessas MPEs a valorização da singularidade, da potencialidade e do bom desempenho das pessoas com deficiência, facilitando o vínculo e diminuindo os preconceitos e possíveis fantasias em relação a elas.

Palavras Chave: Inclusão. Pessoas com Deficiência. Micro e Pequenas Empresas. Vínculo.

\begin{abstract}
Recent studies reveal the low receptivity of companies to the practice of including people with disabilities. However, a survey carried out by the National Federation of Associati of
\end{abstract}


Parents and Friends of the Exceptionl (APAEs) shows that $97.9 \%$ of the small companies, that hire people with disabilities from this institution, have less than 100 workers. The aim of this study was to understand the reasons why managers of small companies with less than 100 employees are hiring people with disabilities, considering that they do not have a legal obligation. Ten small companies' managers from two mesoregions of the state of Minas Gerais participated in the research. Qualitative methods were adopted. Interviews was carried outwith the managers and submitted to content analysis. It was concluded that Normality and Conception of Inclusion were the main Matrixes of Interpretation among managers. Managers hire people with disabilities for two main reasons: knowing the person previously and due to indication and / or influencing of the APAE or another institution. Moreover, what seems to prevail in these small companiesarethe valorizationof the singularity, of the potentiality and the good performanceof the disabled person. This context as facilitated the relationship and has reduced prejudices and has minimized possible fantasies about them.

Keywords: Inclusion. Disabled people. Micro and small companies. Relationship.

\section{INTRODUÇÃO}

Historicamente, a deficiência é associada a uma condição de desvantagem, no sentido em que se refere a uma situação de desvio da normalidade a partir de um esquema comparativo entre pessoas com e sem deficiência (VIOLANTE; LEITE, 2011). Nessas situações, a deficiência remete a déficit/falta, ou seja, o indivíduo é identificado e/ou categorizado com base em algo que falta em seu corpo biológico (RODRÍGUEZ DÍAZ; FERREIRA, 2010), o que denota ausência de conformidade com o que é considerado normalidade e que carrega consigo o status de incapacidade. Assim, a gênese dessa desvantagem é colocada na própria pessoa com deficiência, ao invés de considerar a condição imposta por ambientes sociais pouco adaptados para promover a inclusão (PALACIOS et al., 2012).

De acordo com a Organização Internacional do Trabalho (OIT, 2021), cerca de 15\% de pessoas do mundo possuem algum tipo de deficiência, o que significa algo em torno de um bilhão de pessoas, com cerca de $80 \%$ delas em idade produtiva. No Brasil, o IBGE (2018) estima que cerca de 12,7 milhões de cidadãos possuem deficiência, o que equivale a $6,7 \%$ dos habitantes do país. Considerando a linha de corte recomendada pelo Grupo de Washington, em Minas Gerais, são cerca de 1,6 milhões de pessoas com deficiência. Entretanto, segundo dados da Relação Anual de Informações Sociais relativa ao ano de 2019 apenas 523,4 mil pessoas com deficiência trabalham formalmente no Brasil, correspondendo a um percentual de 1,1\% do total dos vínculos empregatícios (RAIS, 2020), mesmo considerando que o emprego das pessoas com deficiência no Brasil está amparado por lei. A Lei Federal $\mathrm{n}^{\circ} 8.213$ de julho de 1991, também conhecida como Lei de Cotas, estabelece o preenchimento de $2 \%$ a $5 \%$ das vagas do quadro de funcionários de empresas com 100 ou mais funcionários para pessoas com deficiência ou reabilitados.

No cenário de discussão sobre as questões de inclusão, as pesquisas têm direcionado para avaliar as práticas de gestão das organizações no tocante à diversidade e analisado as circunstâncias vividas pelas pessoas com deficiência para se inserirem e se manterem no mercado de trabalho (MACCALI et al, 2015; ÁVILA-VITOR; CARVALHO-FREITAS, 2012), evidenciando a baixa receptividade por parte das empresas com relação à prática de inclusão de pessoas com deficiência, e refletindo, assim, um baixo número de admissões e estratégias de burla das organizações frente à Lei (DUTRA et al, 2020; SUZANO et al, 2014; RIBEIRO; CARNEIRO, 2009). Várias dificuldades são apontadas para a contratação e 
permanência dessas pessoas em organizações, como por exemplo, a falta de conhecimento em relação às possibilidades de trabalho, desconhecimento do que seja a deficiência, presença de barreiras físicas nas organizações, falta de capacitação, entre outras (BECKER, 2019; LORENZO; SILVA, 2017; NEVES-SILVA; PRAIS, SILVEIRA, 2015; FERREIRA; VAN MUNSTER, 2015; PASSERINO; PEREIRA， 2014;; RIBEIRO; CARNEIRO， 2009; CARVALHO-FREITAS; NEPOMUCENO; MARQUES, 2008; GOULART; COIMBRA, 2008).

Numa revisão de literatura realizada por Simonelli e Jackson Filho (2017), buscou-se avaliar as políticas e práticas voltadas à inclusão de pessoas com deficiência no trabalho no Brasil. Constatou-se que, de modo geral, o cumprimento da legislação depende fortemente das ações de fiscalização, ou seja, via de regra, as organizações visam somente atender à lei, sem grandes investimentos e mudanças nos locais de trabalho. De acordo com Tanaka e Manzini (2005), a contratação desse público, tendo em vista apenas o cumprimento do imperativo legal, sem propiciar condições que facilitem o acesso e a permanência dessas pessoas, pode colaborar para acentuar o preconceito vivido por elas em relação a sua competência laboral.

Nesse contexto, um estudo realizado sobre a colocação profissional de pessoas com deficiência intelectual (BEZERRA, 2010), corrobora tais evidências. No entanto, ele revela que, no estado de Minas Gerais, aproximadamente $98 \%$ das empresas que mais empregam pessoas com deficiência têm menos de 100 trabalhadores e, por consequência, não têm a obrigação legal de adotar essa prática. Considerando essa informação que destoa da literatura geral sobre a inserção no trabalho de pessoas com deficiência, objetivou-se compreender os motivos pelos quais gestores de pequenas empresas mineiras contratam pessoas com deficiência, visto que aquelas empresas que são obrigadas a contratar estas pessoas, em função da Lei de Cotas, não têm cumprido, em grande parte dos casos, a legislação. Pesquisar os motivos pelos quais organizações que não são obrigadas a cumprir a Lei de Cotas contratam essas pessoas pode auxiliar a identificar, compreender e trazer subsídios para as práticas de inclusão no cenário do trabalho. Para tanto, serão apresentados o contexto e as referências que foram utilizadas para analisar os motivos pelos quais os empresários contratam pessoas com deficiência quando não são obrigados; método adotado; resultados e discussão e considerações finais, além das referências utilizadas.

\section{REFERENCIAL TEÓRICO}

Revisões históricas têm evidenciado que as pessoas com deficiência foram vistas e tratadas de maneiras diferentes ao longo do tempo (FONSECA, 2006; PESSOTTI, 1984). Elas têm mostrado que há diferentes dinâmicas associadas à forma de se ver a deficiência, as quais têm amplo desdobramento nas ações e atitudes estabelecidas para com estas pessoas.

A partir de uma análise nos diversos períodos históricos, em estudos que contemplaram a deficiência desde a Grécia Antiga até os dias atuais, Carvalho-Freitas e Marques (2007) identificaram que a deficiência é concebida como um processo histórico de atribuição de características e significados ao que é considerado diferente e tem suas bases alicerçadas nas relações de poder vigente, no conhecimento produzido e compartilhado e na maneira como a sociedade está organizada. Compreendeu-se que, devido às mudanças sociais, históricas e na produção do conhecimento, apareciam novas formas de conceber a deficiência, sem, contudo, eliminar a forma anterior de se percebê-la. Pelo contrário, diferentes formas de se ver a deficiência continuavam coexistindo, caracterizando padrões diferentes de comportamento predominantes em relação às pessoas com deficiência em um mesmo período histórico (CARVALHO-FREITAS; MARQUES, 2007). Em função dessa constatação, os autores criaram uma tipologia a qual denominaram matrizes de interpretação da deficiência ou concepções de deficiência, que são modos de pensamento construídos ao longo da história, 
quer sejam fundados em informações e conhecimentos racionais ou não, e que são utilizados para a qualificação das pessoas com deficiência, além de ofereceram as justificativas para as ações em relação a elas, tanto na sociedade quanto no trabalho. Estas concepções trazem implicações de ordem política, social e científica, que marcam e norteiam as práticas sociais.

Considerando essas possibilidades distintas de se conceber a deficiência, na presente pesquisa foi feita a opção por identificar a concepção de deficiência desses empregadores e gestores ao contratar pessoas com deficiência, quando não eram obrigados a fazê-lo. Optouse, então, por utilizar o construto de concepções de deficiência elaborado por Carvalho-Freitas e Marques (2007), uma vez que poderia contribuir para identificar a concepção de deficiência predominante desses gestores. Além disso, essa perspectiva de análise tem sido utilizada em vários estudos, contribuindo para a compreensão da relação estabelecida com pessoas com deficiência em situações de trabalho (ÁVILA-VITOR; CARVALHO-FREITAS, 2012; BRITE, 2009; GOULART; COIMBRA, 2008; NASCIMENTO; DAMASCENO; ASSIS, 2008; RESENDE; CARVALHO-FREITAS; VIEIRA-SILVA, 2015; SILVA; PINTO, 2016).

Carvalho-Freitas (2007) e Carvalho-Freitas e Marques (2007) identificaram seis matrizes de interpretação dominantes ao longo da história, denominadas concepções de deficiência. No Quadro 1 são apresentadas as principais concepções de deficiência, as ações decorrentes de cada concepção e as possibilidades de inclusão das pessoas com deficiência em cada concepção.

Quadro1 - Principais concepções de deficiência

\begin{tabular}{|c|c|c|}
\hline $\begin{array}{c}\text { Matriz de } \\
\text { interpretação } \\
\text { dominante }\end{array}$ & $\begin{array}{c}\text { Ação social } \\
\text { decorrente }\end{array}$ & $\begin{array}{c}\text { Possibilidade de inclusão da } \\
\text { pessoa com deficiência }\end{array}$ \\
\hline $\begin{array}{c}\text { Subsistência/ } \\
\text { Sobrevivência }\end{array}$ & $\begin{array}{c}\text { Ações de exclusão ou } \\
\text { inclusão social com } \\
\text { vistas a propiciar a } \\
\text { manutenção da } \\
\text { sociedade }\end{array}$ & $\begin{array}{c}\text { Integração mediante comprovação de } \\
\text { contribuição social efetiva, por meio do } \\
\text { trabalho }\end{array}$ \\
\hline $\begin{array}{c}\text { Sociedade Ideal e } \\
\text { função instrumental } \\
\text { da pessoa }\end{array}$ & Exclusão social & Ausência de possibilidade de integração \\
\hline Espiritual & Segregação/ caridade & $\begin{array}{c}\text { Segregação em instituições de caridade } \\
\text { separadas da sociedade ou exposição pública } \\
\text { sujeita à compaixão. O sentimento de caridade } \\
\text { é o fator determinante desta matriz }\end{array}$ \\
\hline Normalidade & Segregação & $\begin{array}{c}\text { Segregação em instituições hospitalares ou } \\
\text { psiquiátricas ou inserção mediante sua } \\
\text { "retificação" e adequação social }\end{array}$ \\
\hline /integração & \\
\hline & & \\
\hline
\end{tabular}




\begin{tabular}{|c|c|c|}
\hline Inclusão Social & $\begin{array}{c}\text { Inclusão das pessoas } \\
\text { com deficiência nos } \\
\text { diversos espaços } \\
\text { sociais }\end{array}$ & $\begin{array}{c}\text { Inclusão das pessoas com deficiência a partir } \\
\text { das modificações dos espaços sociais, visando } \\
\text { ser acessível a todos }\end{array}$ \\
\hline Técnica & $\begin{array}{c}\text { Gestão da diversidade } \\
\text { como recurso a ser } \\
\text { administrado nas } \\
\text { organizações de } \\
\text { trabalho }\end{array}$ & $\begin{array}{c}\text { Inclusão no trabalho das pessoas com } \\
\text { deficiência e gestão do trabalho dessas pessoas } \\
\text { como um recurso dentro das organizações }\end{array}$ \\
\hline
\end{tabular}

*As duas primeiras matrizes não foram operacionalizadas para a utilização em pesquisas empíricas. Fonte: Carvalho-Freitas (2007, p. 60).

Algumas pesquisas (CARVALHO-FREITAS; MARQUES, 2010; CARVALHOFREITAS, 2009; NEPOMUCENO; CARVALHO-FREITAS, 2008; ASSIS; CARVALHOFREITAS, 2014) mostram que as concepções de deficiência dos gestores estão vinculadas ao estilo de gestão que possuem e às práticas e condições de trabalho das pessoas com deficiência. Por conseguinte, gestores não preparados para o trabalho com essas pessoas colaboram para a inexistência de ações que contribuam para reais possibilidades de trabalho deste grupo (BAHIA; SANTOS, 2008).

Contudo, principalmente nas pequenas empresas, parece pertinente que as convicções, atitudes e ações de seus gestores sejam influenciadas fortemente por suas crenças pessoais e culturais (BRASKARAN, 2006). Nesse sentido, a hipótese deste estudo era de que as concepções de deficiência predominantes entre os gestores de micro e pequenas empresas e as características das relações que eles estabeleceram ao longo da vida com pessoas com deficiência poderiam ser fatores explicativos para o comportamento diferenciado da inserção dessas pessoas em pequenas empresas.

As micro e pequenas empresas (MPE's) vêm sendo há muito tempo alvo de atenção na economia brasileira devido seu potencial de geração de renda e de emprego. Dados do Serviço de Apoio às Micro e Pequenas Empresas (Sebrae) mostram que no Brasil existem 6,4 milhões de estabelecimentos, dos quais $98 \%$ são micro e pequenas empresas. As MPEs respondem por $52 \%$ dos empregos com carteira assinada no setor privado nacional. Apesar dos números expressivos, o índice de mortalidade dos empreendimentos brasileiros é alto, aproximadamente $1 \mathrm{em}$ cada 4 empresas registradas encerram suas atividades com até dois anos de funcionamento (SEBRAE, 2018). Já as causas para o sucesso dessas organizações estão intimamente ligadas à capacidade destas empresas inovarem nos processos de gestão e no uso de novas tecnologias (WERNKE et al, 2017). Dessa forma, a gestão da diversidade seria uma vantagem competitiva e uma resposta natural às novas demandas relacionadas à crescente diversificação da demografia da força de trabalho. Esta gestão, se bem conduzida, pode gerar aumento da criatividade, flexibilidade e inovação, crescimento organizacional e individual, melhora no marketing junto aos clientes e aperfeiçoamento na capacidade de se ajustar com rapidez e sucesso às mudanças de mercado (THOMAS; ELY, 1996; TRIGUEROSÁNCHEZ et al, 2018). Para os autores, portanto, não basta apenas que os "diversos" sejam admitidos na empresa, mas as suas contribuições devem ser reconhecidas e incorporadas aos processos organizacionais. Essa diferenciação traz à tona reflexões sobre possíveis ações para diminuir o preconceito e promover a efetiva inclusão dos profissionais com deficiência.

Inúmeras pesquisas internacionais têm, desde o trabalho de Allport (1954), identificado a relevância do contato intergrupos para minimização do preconceito (PETTIGREW, 1997; PETTIGREW; TROPP, 2006; PETTIGREW et al, 2011). Por contato 
intergrupal, entende-se o contato entre pessoas caracterizadas como pertencentes a grupos distintos, tendo como referência características socialmente relevantes. $\mathrm{Na}$ presente investigação, pessoas com e sem deficiência.

As pesquisas sobre contato intergrupal, que inicialmente focavam nas relações entre grupos culturais e raciais diferentes, passaram também a contemplar outros grupos estigmatizados como idosos, pessoas com deficiência, doentes mentais e homossexuais (PETTIGREW et al, 2011). Allport (1954) defendeu a premissa de que o contato intergrupal para reduzir atitudes negativas precisava atender quatro condições: (a) status igual entre os grupos na situação; (b) objetivos comuns; (c) não competição entre os grupos; e (d) sanção legal para os contatos. As pesquisas têm indicado que essas condições facilitam a relação, embora não seja estritamente necessária a presença de todas elas (PETTIGREW, 1997; PETTIGREW; TROPP, 2006; VEZZALI; STATHI, 2017).

Por outro lado, o pequeno contato intergrupal reforça os preconceitos existentes, retroalimentando o processo de discriminação (FICHTEN; SHIPPER; CUTLER, 2005). A falta de oportunidade de convivência transforma o contato inicial com as pessoas com deficiência em um processo permeado de insegurança e ansiedade frente a essa realidade desconhecida, sublinhando a origem social da discriminação (HUGHES, 2012). Assim, a ausência de contato com pessoas com deficiência, devido ao histórico de exclusão desse grupo, impossibilita a construção de uma representação do outro a partir de relação concreta ao longo do tempo e abre espaço para a presença de fantasias e expectativas sem fundamento, materializado na relação e sem possibilidade de ressignificação. Esse processo caracteriza a formação de vínculos repletos de ruídos e permeados de receios (PICHÓN-RIVIĖRE, 1988).

A noção de vínculo surge, então, como uma importante unidade de análise. Para Alves (2009), essa teoria possibilita entender que, a partir do convívio com outros sujeitos, o indivíduo consegue perceber a interseção existente entre sua própria história pessoal e a história social de outras pessoas com as quais passa a se relacionar. O vínculo para PichónRivière (1988) é considerado uma estrutura bi-corporal e tri-pessoal. Entende-se que a interação entre duas pessoas (bi-corporal) é afetada por uma terceira pessoa, a qual se apresenta nessa relação como ausente-presente. Essa terceira pessoa são as expectativas, fantasias, preconcepções que se tem do outro e que interferem na relação, por isso ausente (como corpo físico), mas presente (como uma terceira pessoa que encarna as fantasias do mundo interno do sujeito). Fantasia é um conceito utilizado por Pichón-Rivière (1988, 1988a) para se referir às avaliações e receios em relação ao outro, sem correspondência de realidade. Quanto menores as fantasias e maior o critério de realidade utilizado em relação ao comportamento do outro, maior a possibilidade de construção de vínculos sem interferências de ruídos e mal-entendidos.

Considerando que há uma predominância de ausência de contato entre pessoas com e sem deficiência e que as pessoas com deficiência diferem do estereótipo de homem típico presente na história de aprendizagem da maioria das pessoas, restam apenas as fantasias construídas a partir do senso-comum, sendo uma relação permeada por sentimento de perigo e ameaça, resultando na produção de impasses na aproximação entre as pessoas (RUDGE, 1992). Ameaça entendida, a partir de Pichón-Riviêre (1988a), como o medo do ataque (ser agredido, ser "contagiado" pelo outro) e pelo medo da perda (perda da ausência de conforto por não saber como se relacionar, como agir com o outro que é diferente). Pichón-Rivière (1988) entende que a diminuição das fantasias em relação ao outro é que possibilita uma comunicação sem ruídos e um processo de aprendizagem contínuo em que é possível transformar-se e transformar o contexto social. No entanto, esse processo apenas é possível em relações concretas e historicamente situadas. 


\section{MÉTODO}

A abordagem adotada no desenvolvimento da pesquisa foi qualitativa, visando ao entendimento das concepções predominantes de deficiência, contato e vínculo dos gestores de pequenas empresas em relação às pessoas com deficiência. Não foram encontrados na literatura estudos que abordassem a inserção de pessoas com deficiência em empresas desse porte.

\section{Participantes}

Este estudo foi realizado em quatro cidades de Minas Gerais, situadas nas mesorregiões do Campo das Vertentes e Metropolitana de Belo Horizonte. De acordo com o censo realizado em 2010, pelo Instituto Brasileiro de Geografia e Estatística (IBGE), estimase que duas dessas cidades possuem um número superior a 120 mil habitantes, uma inferior a 90 mil e outra com a população inferior a 50 mil habitantes. A escolha dessas cidades foi por conveniência, devido à facilidade de acesso dos pesquisadores e às características das cidades que possuíam muitas empresas de pequeno porte com variadas atividades econômicas.

O critério de inclusão dos participantes da pesquisa foi ser gestor de micro e pequenas empresas, escolhidas por conveniência, isto é, que tinham pessoas com deficiência em seu quadro de pessoal, além de terem um número inferior a 100 funcionários (não serem legalmente obrigadas a contratar pessoas com deficiência). Participaram deste estudo 10 gestores de 10 micro e pequenas empresas. Quatro empresas foram sugeridas pela Associação de Pais e Amigos dos Excepcionais (APAE) das cidades. A identificação das demais foi feita por meio de indicação dos gestores entrevistados (bola de neve).

No que se refere à caracterização sociodemográfica dos gestores, dos 10 participantes, sete são do sexo masculino, cinco possuem acima de 45 anos de idade, seguidos por aqueles que possuem idade entre 36 e 40 anos (três participantes). No que se refere ao estado civil, sete pesquisados são casados e os demais são separados, divorciados ou desquitados. Quanto à escolaridade, seis possuem curso superior ou algum título de pós-graduação como, por exemplo, especialização, mestrado ou doutorado. Em relação ao nível salarial, a amostra é bem distribuída: dois recebem até dois salários mínimos; dois recebem de 3 a 5 salários mínimos; dois recebem de 6 a 8; outros dois de 9 a 12; e dois acima de 20 salários mínimos. Quatro dos entrevistados afirmaram morar na mesma residência com mais três pessoas e outros quatro relataram morar com 3 a 5 pessoas na mesma casa. Metade dos sujeitos possui alguma pessoa com deficiência na família, sendo que quatro deles possuem um familiar com deficiência física e um participante possui um familiar com deficiência auditiva. Esse resultado ratifica a importância dos vínculos entre pessoas com e sem deficiência, pois minimiza preconcepções e amplia a participação das pessoas com deficiência, baseada em possibilidades reais de participação e contribuição.

Sobre o porte das empresas, não há um consenso no Brasil. O conceito de micro e pequena empresa (MPE) pode sofrer variação de acordo com a perspectiva ou critérios adotados, como: número de empregados, faturamento, setor de atividade, lucro, patrimônio líquido, dentre outros (RODARTE, 2012; CAMPOS et al, 2008; CESARINO; CAMPONAR, 2006). Rodarte (2012) explica que, para fins de estudo, a classificação mais utilizada se baseia a partir do número de funcionários que a empresa possui. Por isso, adotou-se na presente pesquisa a classificação do Serviço Brasileiro de Apoio às Micro e Pequenas Empresas SEBRAE (2013), que especifica como microempresa aquela que tem até 19 funcionários (no setor de indústria) e até 9 funcionários (nos setores de comércio e serviços) e como pequena empresa aquela que possui de 20 a 99 funcionários (no setor de indústria) e de 10 a 49 funcionários (nos setores de comércio e serviços). 
Das empresas participantes da pesquisa, oito estão no setor do comércio. Em relação ao número de funcionários, seis possuem menos de 9 funcionários, constituindo, de acordo com o SEBRAE, como uma microempresa. Sete podem ser consideradas empresas de tradição, já que atuam há mais de 20 anos no mercado.

\section{Procedimentos de coleta de dados}

Os participantes desta pesquisa foram convidados a responder um questionário contendo dados sociodemográficos e uma entrevista semiestruturada, com questões sobre os motivos da contratação de pessoas com deficiência na empresa, a forma como viam a deficiência (concepções de deficiência) e como avaliavam o trabalho com essas pessoas (contato e vínculo estabelecido). O questionário com dados sociodemográficos foi desenvolvido especificamente para a presente pesquisa. Parte do roteiro de entrevista foi construído a partir do Inventário de Concepções de deficiência (CARVALHO-FREITAS, 2012). Foram escolhidos um ou dois itens de cada fator para a realização das perguntas. Por exemplo, "você considera que a contratação de pessoas com deficiência melhora a imagem da empresa junto aos clientes? E foram acrescentadas as seguintes interrogações para cada item: Por que? Você pode me dar exemplos? Foram também incluídas perguntas sobre o contato e o vínculo com os trabalhadores com deficiência contratados. O questionário e a entrevista foram aplicados em sequência, na empresa (em local sem a presença de outras pessoas). A aplicação durou em média uma hora e trinta minutos, sendo as entrevistas gravadas, com o consentimento dos entrevistados, e transcritas posteriormente. A pesquisa foi aprovada por Comitê de Ética e atendeu aos requisitos de participação livre e esclarecida.

\section{Procedimentos de análise de dados}

A análise das entrevistas realizadas foi feita a partir da análise temática de conteúdo que, segundo Bardin (1977), pode ser definida como um processo em que a palavra é mediadora do sentido, e que se utiliza de procedimentos sistemáticos e objetivos de descrição do conteúdo das mensagens. As mensagens são reunidas em categorias baseadas na recorrência dos temas verbalizados pelos entrevistados. A partir da análise de conteúdo, foram identificados o aparecimento de várias informações sobre o perfil das pessoas, por exemplo, falavam da formação das pessoas com deficiência, do que faziam, etc. Além disso, contavam porque haviam contratado essas pessoas e também respondiam às questões sobre concepções de deficiência. A partir dessas recorrências foram construídas três categorias de análise: perfil das pessoas com deficiência contratadas; motivos da contratação e concepções de deficiência dos gestores.

\section{RESULTADOS E DISCUSSÃO}

A seguir serão apresentadas e discutidas as categorias identificadas na análise de conteúdo.

\section{Perfil das pessoas com deficiência contratadas}

Em relação ao número de pessoas com deficiência que trabalham nas micro e pequenas empresas, nove possuem apenas um funcionário com deficiência, sendo que uma delas possui dois. O comércio se mostrou o ramo de atividade que mais contratou (80\%) nessa pesquisa, embora, segundo a RAIS (2018) ele seja o segundo maior setor econômico que contratou trabalhadores no país em 2018, depois do setor de Serviços. Sobre o tempo de serviço dessas pessoas nas MPEs pesquisadas, verificou-se que cinco trabalham de um a cinco anos nas empresas; seguidas por duas que trabalham há mais de 20 anos, as três outras, trabalham em tempos variados. 
Ratificando pesquisas anteriores (PASSERINO; PEREIRA, 2014; RIBEIRO; CARNEIRO, 2009; SIMONELLI; JACKSON FILHO, 2017), a grande maioria das pessoas com deficiência não possui um alto grau de escolaridade e ocupam funções que não exigem grandes qualificações (vide Quadro 2).

Quadro 2 - Relação entre o tipo de deficiência, o grau de escolaridade e a função desempenhada

\begin{tabular}{|c|c|c|}
\hline Tipo de Deficiência & Grau de Escolaridade & Função desempenhada \\
\hline Física & E. Médio Completo & Operador de Caixa \\
\hline Física & E. Médio Completo & Vendedor \\
\hline Física & E. Médio completo & Secretária \\
\hline Física & E. Fundamental Incompleto & Ordenhador \\
\hline Visual & E. Superior Completo & Caixa \\
\hline Visual & E. Fundamental Completo & Acabador \\
\hline Intelectual & Não respondeu & Ajudante de entrega / Office boy* \\
\hline Intelectual & E. Fundamental Incompleto & Ajudante de Recepcionista \\
\hline Auditiva & E. Fundamental Incompleto & Carregador de depósito \\
\hline Visual & Não respondeu & Telefonista \\
\hline
\end{tabular}

*são dois funcionários com deficiência intelectual, cada um ocupando um dos cargos citados. Fonte: Dados da Pesquisa

De uma forma geral, verifica-se que o perfil das pessoas contratadas pelas pequenas empresas não difere do perfil de empresas maiores e que estão obrigadas a contratar pessoas com deficiência, mostrando que o perfil dessas pessoas não é um fator distintivo para a decisão de contratação. Embora não façam uso da Lei de Cotas, sete dos gestores concordam muito que a Lei de Cotas para pessoas com deficiência seja uma ação positiva do Estado para garantir igualdade de oportunidades para essas pessoas. Quatro disseram que possuem informações suficientes sobre as questões relacionadas à deficiência e que isso lhes permite lidar com tranquilidade com elas. Sobre a experiência que possuem com essas pessoas, a grande maioria dos gestores (nove) concorda totalmente que a experiência foi positiva e apenas um discorda um pouco dessa afirmação.

\section{Motivos da contratação}

Segundo os dados da pesquisa, existem dois motivos principais que levam as micro e pequenas empresas de Minas Gerais a contratarem pessoa com deficiência: relação afetiva (por conhecer a pessoa previamente); e indicação e/ou influência da APAE ou outra instituição. 
As entrevistas revelaram que grande parte dos gestores (sete) já conhecia as pessoas com deficiência ou tiveram boas referências delas.

Eu já conhecia o trabalho dele e ele é muito bom. Então foi pelo fato de eu já o conhecê-lo. Entendeu? (Gestor 2)

Eu já conhecia o trabalho dela. Um amigo me indicou e disse do excelente trabalho que ela desempenha. Ela é uma pessoa fantástica! E não é a deficiência que ela possui que vai desqualificá-la... (Gestor 10)

Grande parte dos gestores demonstrou a importância do contato estabelecido anteriormente com a pessoa com deficiência que passou a fazer parte do quadro de funcionários de suas empresas e atribuiu ao contato diário com essas pessoas a possibilidade de ratificar a percepção positiva que tinham a respeito delas. Ishige e Hayashi (2005) enfatizaram que a possibilidade de contato prévio com pessoas com deficiência, e mais importante, a qualidade desse contato, são fatores que influenciam no desenvolvimento de atitudes mais favoráveis em relação a essas pessoas. Allport (1954) também já afirmava que o contato social com pessoas com deficiência poderia promover percepções mais positivas dessas pessoas. Esses resultados ratificam as premissas defendidas pelos autores, já que essas pessoas já faziam parte dos mesmos grupos anteriormente, como mesma igreja, mesma comunidade ou relação de amigos. Possivelmente, a experiência anterior com essas pessoas facilitou o vínculo e diminuiu as possíveis fantasias em relação a elas, minimizando os preconceitos e facilitando a contratação.

Percebe-se, no âmbito da presente pesquisa, que o contato anterior possivelmente refletiu em posturas mais inclusivas por parte dos gestores, o que resultou numa maior facilidade no processo de inserção delas no trabalho. Além disso, o contato no ambiente laboral sustentou a percepção de bom desempenho dos funcionários com deficiência.

Também foi identificada a influência que instituições, como a APAE, exercem em relação à inclusão no mercado de trabalho. Foi possível observar que elas funcionam como importantes ferramentas no âmbito das empresas da cidade e região em que se localizam. O gestor 3 disse: "contratamos por meio da APAE. Eu já tive vários contratos com a APAE, que os funcionários vieram, outros foram embora para outras firmas e estes que estão aqui agora são fixos". A possibilidade de inserção, mesmo em organizações que não são obrigadas a contratar pessoas com deficiência, mostra a importância de instituições como a APAE na inclusão social dessas pessoas ao visar desenvolver nelas habilidades e competências para qualificação profissional e atuação no mercado de trabalho, além de fazer um trabalho de sensibilização das empresas para a contratação dessas pessoas. Após décadas de existência, as APAEs acumularam conhecimentos e práticas em defesa dos direitos das pessoas com deficiência e têm um papel importante principalmente nas cidades pequenas, nas quais funcionam como a principal via de apoio a essas pessoas. A intermediação institucional tem sido efetiva na ampliação das possibilidades de trabalho das pessoas com deficiência, mesmo quando as empresas não são obrigadas a contratá-las (BEZERRA, 2010).

\section{Concepções de deficiência dos gestores}

Em relação à forma como veem a deficiência verificou-se que as concepções predominantes foram as de normalidade, inclusão e técnica (desempenho das pessoas com deficiência). A análise das entrevistas permitiu identificar que a referência a uma determinada concepção de deficiência está sempre relacionada a um contexto específico, por exemplo, necessidade de adequação ao cargo; condições para o exercício do trabalho; e o desempenho propriamente dito. 
No que se refere à Normalidade como Matriz de Interpretação, sete gestores explicitaram a necessidade de adequação da deficiência ao trabalho (cargo a ser desempenhado), indicando que, no contexto da contratação, a deficiência ganha centralidade na avaliação dos gestores.

Elas devem desempenhar um trabalho condizente com a deficiência que possuem. (Gestor 3)

Elas devem desempenhar um trabalho de acordo com a sua deficiência. (Gestor 8)

Esses resultados também foram encontrados em empresas de grande porte, em que a questão da normalidade ainda é uma premissa por excelência utilizada para avaliar as possibilidades de trabalho das pessoas com deficiência (ASSIS; CARVALHO-FREITAS, 2014; CARVALHO-FREITAS, 2009). No entanto, a maioria dos gestores explicitou a necessidade de adequação das condições de trabalho e a responsabilidade das organizações nesse processo, o que reflete as premissas da Inclusão Social como Matriz de Interpretação, que considera a importância de um contínuo investimento em ações que assegurem a igualdade de oportunidades.

Com as adequações necessárias, não há diferença entre uma pessoa com deficiência e uma pessoa sem deficiência. Com as devidas condições, não há deficiência para o trabalho. (Gestor 6)

Ele é um vendedor externo e ele tem deficiência no braço e isso não atrapalhava ele dirigir, o carro é adaptado e tudo normal. (Gestor 7)

Essa premissa de que um bom resultado das pessoas com deficiência dentro das organizações depende da adequação das condições de trabalho para elas, reafirma estudos anteriores (CARUSO, 2012; CARVALHO-FREITAS; MARQUES, 2010; CARVALHOFREITAS, 2009; BRITE, 2009; CARVALHO-FREITAS; MARQUES, 2009; LARA; ÁVILA; CARVALHO-FREITAS, 2008).

Também falaram sobre o desempenho e sobre as expectativas de produtividade e qualidade do trabalho dos funcionários com deficiência. De uma maneira geral, os gestores se mostraram confiantes, caracterizando suas expectativas como boas ou "as melhores possíveis". Vale ressaltar que, como essas empresas possuem poucos funcionários, o gestor acompanha minuciosamente o trabalho de todos, o que pode facilitar tanto a performance quanto o contato com as singularidades de cada empregado e, consequentemente, a avaliação de cada um.

Dos gestores entrevistados, seis avaliaram o trabalho das pessoas com deficiência com frases que demonstram um bom desempenho. Percebeu-se uma tendência forte de comparar o trabalho desenvolvido por uma pessoa com deficiência ao de uma pessoa sem deficiência. Isso fica evidente nas seguintes falas:

No caso dele, em comparação com os demais, não tem diferença nenhuma. (Gestor 4)

Eu lido com ela como se fosse uma pessoa normal. Minhas expectativas são as mesmas em relação aos demais funcionários. (Gestor 5)

Observou-se, ainda, a elevada valorização do trabalho da pessoa com deficiência, atribuindo a ela um caráter de supervalorização, como na fala do gestor 2: "as melhores possíveis. É o mais atento, é o que faz com mais zelo o serviço, entendeu?"

As falas demonstram não haver percepção negativa em relação ao desempenho, contrariando pesquisas que indicam que as pessoas com deficiência costumam ser 
desfavorecidas na avaliação de seu desempenho. Conforme Jones, Latreille e Sloane (2006), quando um trabalhador tem deficiência, os gestores podem ter baixas expectativas sobre seu desempenho, as quais são baseadas na relação entre a deficiência e a capacidade para atender às expectativas de determinada função. Por outro lado, Stone-Romero, Stone e Lukaszewski (2006) sugerem que os gestores têm alto grau de exigência do desempenho e que comumente tem sua performance considerada negativa. Thomas e Chrobot-Mason (2005) explicam que em situações nas quais membros de grupos minoritários representam uma pequena porcentagem da força de trabalho, estes membros são encarados com exageradas doses de expectativas (muito altas ou muito baixas), e são altamente criticados e examinados de forma não realista. Estas expectativas podem afetar negativamente as relações de trabalho e a performance organizacional.

Também Suzano et al (2014) identificou que a avaliação de desempenho feita por gestores dos diferentes tipos de deficiência tende a melhorar quando eles atuam com essas pessoas, ao contrário de quando avaliam baseados em estereótipos construídos sobre um possível desempenho que elas teriam. Na presente pesquisa, verifica-se que o contato intergrupos fez com que a avaliação fosse particularizada e que levasse em conta a realidade vivida, tornando essa avaliação mais positiva.

Por outro lado, a comparação entre pessoas com e sem deficiência parece ser um artifício utilizado para demonstrar que o desempenho das pessoas com deficiência também é positivo, a despeito de sua diferença funcional. Como a inserção no trabalho é um processo relativamente novo, considerando a história da exclusão dessas pessoas, entende-se que a comparação seja um processo de ajustamento perceptivo e de possibilidade de ressignificação da deficiência de incapacitante para não-incapacitante, abrindo possibilidades reais de inclusão.

\section{CONSIDERAÇÕES FINAIS}

A presente investigação permitiu identificar que, dentre as micro e pequenas empresas participantes, os motivos pelos quais os gestores contratam pessoas com deficiência, embora não tenham obrigação legal, estão relacionados a dois fatores principais: relação afetiva, por conhecer a pessoa previamente, e indicação e/ou influência da APAE.

O primeiro motivo observado nas MPEs está relacionado a um contato anterior dos gerentes com essas pessoas, tanto por intermédio de conhecidos, quanto pelo fato de conhecerem a pessoa com deficiência, por frequentarem os mesmos locais e/ou pertencerem ao mesmo grupo comunitário, por exemplo. Nesse contexto, a atitude de incluí-las sem obrigação legal respalda um reconhecimento das possibilidades das pessoas com deficiência para as diferentes atividades. A inclusão laboral foi, portanto, decorrente basicamente do contato anterior com pessoas com deficiência em outras esferas da vida. A possibilidade de interagir com pessoas com deficiência na escola, no lazer e na comunidade facilitou o processo de interação dentro do ambiente de trabalho, o que referenda o conjunto de medidas afirmativas visando à inclusão de pessoas com deficiência nos diversos espaços sociais. Já o segundo motivo relaciona-se às ações que buscam qualificar pessoas com deficiência, oferecendo escolarização e treinamento, fomentadas por instituições como a APAE, que também fazem um trabalho de sensibilização e divulgação das possibilidades de trabalho dessas pessoas. Essas ações mostram-se importantes para a inclusão, uma vez que o efeito tem sido o aumento do número de pessoas com deficiência qualificadas e preparadas para desempenhar uma gama cada vez maior de atividades laborais.

Além disso, verificou-se que as concepções de deficiência são dependentes do contexto de análise do gestor, indicando que é possível, do ponto de vista subjetivo, ter várias concepções de deficiência sem causar um conflito interno nas pessoas. Por exemplo, verificou-se que existe uma tendência em compartilhar dos pressupostos da matriz de 
normalidade quando da contratação das pessoas com deficiência, conferindo uma centralidade maior à deficiência, embora, nos casos das MPEs investigadas, já existir uma aposta bastante positiva nas potencialidades dessas pessoas, pois elas são contratadas sem nenhuma obrigação legal. Uma vez contratada, a matriz de inclusão e a concepção de desempenho passam a ser as concepções predominantes, buscando oferecer condições de trabalho adequadas para favorecer o melhor desempenho das pessoas. Essa plasticidade na forma de conceber a deficiência reafirma a importância do contato prévio com essas pessoas e o acolhimento das indicações das APAEs, o que contribui para a minimização dos preconceitos em relação às pessoas com deficiência.

Estes resultados podem contribuir para práticas de inclusão também das grandes empresas, pois mostram que a efetiva participação das pessoas com deficiência no contexto laboral depende, em grande medida, da valorização e do suporte oferecido a elas. Embora não haja o imperativo legal, a atitude destas micro e pequenas empresas demonstram uma postura relacionada ao reconhecimento dos gestores de que as pessoas com deficiência também estão aptas para o trabalho. Ao contrário das grandes empresas, as quais geralmente possuem um contexto organizacional mais amplo que inclui políticas e estratégias junto ao mercado e aos funcionários e capital para investimento em modificações das condições de trabalho (HANASHIRO; GODOY, 2004), o que parece prevalecer nessas MPEs é uma cultura de valorização da singularidade e da potencialidade da pessoa com deficiência. Assim, é ofertada a pessoa com deficiência a possibilidade de se inserir num posto de trabalho real e, a partir daí, é provido ao indivíduo apoio e suporte nessa integração, de forma a fazê-lo conquistar uma progressiva independência no desempenho laboral e competências básicas a ele associadas.

Esses resultados referendam a importância determinante do contato e da disposição positiva em relação às pessoas com deficiência como elementos centrais na inclusão de pessoas com deficiência no trabalho. Esses fatores podem oferecer elementos para as organizações construírem processos de sensibilização em que possam estar presentes pessoas com deficiência que compartilhem com gestores e funcionários suas estratégias de adaptação e suas formas de lidar com o mundo que, embora consideradas atípicas, permitem uma existência digna e com possibilidades de contribuição para a sociedade, de uma maneira geral. Essa possibilidade de contato, ainda que em situações artificiais de treinamento, podem fazer o papel do contato que os gestores de MPEs tiveram com essas pessoas em seus cotidianos de vida, fazendo-os cogitar a possibilidade de vir a trabalhar com elas. Mais do que treinamentos falando da obrigação legal e dando dicas de como lidar e tratar pessoas com deficiência, a possibilidade de contato positivo com essas pessoas, parece efetivamente contribuir para uma mudança na forma de conceber as possibilidades de trabalho das pessoas com deficiência.

É importante salientar, contudo, alguns limites deste estudo, como o número pequeno de participantes. A reaplicação desta pesquisa em outros contextos, como, por exemplo, em outras Mesorregiões ou outros Estados, poderá contribuir para o aprimoramento deste trabalho. Além disso, poderá ser reaplicado comparando a percepção dos gestores e dos colegas de trabalho das pessoas com deficiência nas micro e pequenas empresas. Outras pesquisas são importantes para contribuírem e para ampliarem o conhecimento sobre essa temática.

\section{NOTAS}

${ }^{1}$ Em 2018, o IBGE divulgou Nota Técnica (01/2018) corrigindo o número de pessoas com deficiência no país que havia sido levantado no Censo de 2010. Essa correção obedeceu às recomendações do Grupo de Washington que busca padronizar metodologias com vistas a permitir a comparabilidade das estatísticas entre os países (IBGE, 2018). 


\section{REFERÊNCIAS}

ALLPORT, G. The nature of prejudice. Cambridge: Addison-Wesley, 1954.

ASSIS, A. M.; FREITAS, M. N. C. Estudo de caso sobre a inserção de pessoas com deficiência numa organização de grande porte. REAd. Revista Eletrônica de Administração, v. 20, n. 2, p. 496-528, 2014.

ÁVILA-VITOR，M. R. C.; CARVALHO-FREITAS，M. N. Valores organizacionais e concepções de deficiência: a percepção de pessoas incluídas. Psicologia, Ciência e Profissão, Brasília, v. 32, n. 4, p. 792-807, 2012.

BAHIA, M. S.; SANTOS, E. M. Práticas empresariais para inclusão profissional de pessoas com deficiência: um estudo de caso. In: CARVALHO-FREITAS, M. N.; MARQUES, A. L. (Orgs.). Trabalho e pessoas com deficiência: pesquisas, práticas e instrumentos de diagnóstico. Curitiba: Juruá, p. 142-160, 2008.

\section{BARDIN, L. Análise de conteúdo. Lisboa: Edições 70. 1977}

BECKER, K. L. Como a deficiência afeta a educação e o trabalho de jovens no Brasil. Nova economia, v. 29, n. 3, 2019.

BEZERRA, S. S. A nova "ralé" das organizações do trabalho: um estudo sobre a colocação profissional da pessoa com deficiência intelectual. 2010. Dissertação (Mestrado Executivo em Gestão Empresarial). Escola Brasileira de Administração Pública e de Empresas, Rio de Janeiro, RJ, Brasil, 2010.

BRASKARAN, S. Incremental Innovation and business performance: small and mediumsized enterprises in a concentrated industry environment. Journal of Small Business Management, v. 4, n.1, p. 64-80, 2006.

BRASIL. Lei $\mathrm{n}^{\circ} 8.213$ de 24 de julho de 1991 (Lei das Cotas). Dispõe sobre os planos de benefícios da Previdência Social e dá outras providências. Diário Oficial [da] União, Brasília, DF: 1991. Disponível em: <http://www.planalto.gov.br/ccivil/LEIS/L8213.htm>. Acesso em: 05. Jul. 2017.

BRASIL. Ministério do Trabalho e Emprego. (Org.). Características do Emprego Formal RAIS, 2018: Pessoas com Deficiência. Brasil, 2018. Disponível em http://pdet.mte.gov.br/rais/rais-2018. Acesso em 30 de julho de 2021.

BRASIL. Ministério do Trabalho e Emprego. (Org.). Características do Emprego Formal RAIS, 2019: Pessoas com Deficiência. Brasil, 2020. Disponível em http://pdet.mte.gov.br/rais?view=default. Acesso em 30 de julho de 2021.

BRITE, R. B. Análise das Concepções de Gestores sobre deficiência em pessoas que ocupam postos de trabalho em uma rede de supermercados. Dissertação (Programa de Pós-graduação em Políticas Públicas e Formação Humana). Faculdade de Educação, Universidade do Estado do Rio de Janeiro, RJ, 2009. 
CAMPOS, J. G. F.; NISHIMURA, A. T.; RAMOS, H. R.; CHEREZ, R. L.; SCALFI, V. B. As pequenas e médias empresas no Brasil e na China: uma análise comparativa. São Paulo: Universidade de São Paulo. 2008. Disponível em: http://www.ead.fea.usp.br/eadonline/grupodepesquisa/publica\%C3\%A7\%C3\%B5es/Heidy/18 .pdf. Acesso: 26/12/ 2020.

CARUSO, A. Reverberações da Lei $\mathbf{n}^{0}$ 8.213/91 à luz das concepções de deficiência: estudo de caso no contexto do projeto de sensibilização gerencial em uma organização privada de ensino profissionalizante. 2012, 260p. Tese (Doutorado em Políticas Públicas e Formação Humana), Universidade do Estado do Rio de Janeiro, Rio de Janeiro, 2012.

CARVALHO-FREITAS, M. N. A Inserção de pessoas com deficiência em empresas brasileiras - Um estudo sobre as relações entre concepções de deficiência, condições de trabalho e qualidade de vida no trabalho. 2007. 314 p. Tese (Doutorado em Administração) - Faculdade de Ciências Econômicas, Centro de Pós-Graduação e Pesquisas em Administração, Universidade Federal de Minas Gerais, Belo Horizonte, 2007.

-. Validação do Inventário de Concepções de Deficiência em Situações de Trabalho (ICD-ST). Psico-USF, v. 17, n. 1, p. 33-42, jan./abr. 2012.

Inserção e Gestão do Trabalho de Pessoas com Deficiência: um Estudo de Caso. RAC - Revista de Administração Contemporânea, Curitiba, v. 13, Edição Especial, p. 121138, Jun. 2009.

.; NEPOMUCENO, M. F; MARQUES, A. L. Suposições básicas sobre a natureza do comportamento humano e sobre o trabalho de PCDs. In: ENCONTRO ANUAL DA ASSOCIAÇÃO NACIONAL DOS PROGRAMAS DE PÓS-GRADUAÇÃO EM ADMINISTRAÇÃ̃O, 32, 2008, Rio de Janeiro. Anais Eletrônicos. Rio de Janeiro: ANPAD, 2008.

.; MARQUES, A. L. A diversidade através da história: a inserção no trabalho de pessoas com deficiência. Organizações \& Sociedade, Salvador, v. 14, n. 41, p. 59-78, Junho 2007.

.; MARQUES, A. L. Pessoas com Deficiência e Trabalho: Percepção de Gerentes e Pós-Graduandos em Administração. Psicologia Ciência e Profissão, v. 29, n. 5, p. 244 - 257, fev. 2009.

.; MARQUES, A.L. Formas de ver as pessoas com deficiência: um estudo empírico do construto de concepções de deficiência em situações de trabalho. Revista de Administração Mackenzie (RAM), São Paulo, v.11, n.3, p.100-129, maio/jun. 2010

CESARINO, L. O.; CAMPONAR, M. C. Micro e pequenas empresas: características estruturais e gerenciais. $2006 . \quad$ Disponível em: http://www.unifafibe.com.br/revistasonline/arquivos/hispecielemaonline/sumario/10/1904201 $\underline{0081633 . p d f}$

DUTRA, F. C. M. S. et al. Oportunidades no mercado de trabalho: análise das vagas de emprego disponíveis para pessoas com deficiência. Cadernos Brasileiros de Terapia Ocupacional [online]. v. 28, n. 1, p. 147-163, 2020. 
FEDERAÇÃO NACIONAL DAS APAES (Fenapaes). Educação Profissional e Trabalho para pessoas com Deficiências Intelectual e Múltipla. Brasília, DF: FENAPAES. 2007.

Acessibilidade para pessoas com deficiência intelectual no mundo do trabalho: orientação para empresas. Brasília, DF: FENAPAES. 2007.

FERREIRA, E. F.; VAN MUNSTER, M. Métodos de avaliação do comportamento adaptativo em pessoas com deficiência intelectual: uma revisão de literatura. Revista Educação Especial, 2015.

FICHTEN, C. S.; SCHIPPER, F.; CUTLER, N. Does volunteering with children affect attitudes toward adults with disabilities? A prospective study of unequal contact. Rehabilitation Psychology, v. 50, n. 2, p. 164-173, 2005.

FONSECA, R. T. M. O trabalho da pessoa com deficiência e a lapidação dos direitos humanos: o direito do trabalho, uma ação afirmativa. São Paulo: LTr, 2006.

GOULART, I.B; COIMBRA, C.E.P. Inserção de Pessoas com Deficiência numa Empresa de Reflorestamento: um Estudo de Caso. Rio de Janeiro/RJ. EnANPAD, 2008.

HUGHES, B. Fear, pity and disgust: emotions and the non-disabled imaginary. In WATSON, N.; ROULSTONE, A.; THOMAS, C.(Orgs.), Routledge. In: Handbook of Disability Studies. New York: Taylor and Francis, 2012. p. 67-77.

IBGE - INSTITUTO BRASILEIRO DE GEOGRAFIA E ESTATÍSTICA. Releitura dos dados de pessoas com deficiência no Censo Demográfico 2010 à luz das recomendações do Grupo de Washington - Nota Técnica 01/2018, 2018. 1-8. Retrieved from ftp://ftp.ibge.gov.br/Censos/Censo_Demografico_2010/metodologia/notas_tecnicas/nota_tecn ica_2018_01_censo2010.pdf

IBGE- INSTITUTO BRASILEIRO DE GEOGRAFIA E ESTATÍSTICA. As Micro e pequenas empresas comerciais e de serviços no Brasil: 2001 / IBGE, Coordenação de Serviços e Comércio. Rio de Janeiro, 2003.

ISHIGE, N.; HAYASHI, N. Occupation and social experience: Factors influencing attitude towards people with schizophrenia. Psychiatry and Clinical Neurosciences, v. 59, p. 89-95, 2005 .

LARA, G. B.; ÁVILA, M. R. C.; CARVALHO-FREITAS, M. N. A questão cognitiva e afetiva na inserção das pessoas com deficiência no mercado de trabalho. Psicologia em Pesquisa, v. 2, n. 1, p. 46-59, 2008.

LORENZO, S. M.; SILVA, N. R. Contratação de Pessoas com Deficiência nas Empresas na Perspectiva dos Profissionais de Recursos Humanos. Revista Brasileira de Educação Especial [online], v. 23, n. 3, p.345-360, 2017.

MACCALI, N.; KUABARA, P. S. S.; TAKAHASHI, A. R. W.; ROGLIO, K.; BOEHS, S. T. M. As práticas de recursos humanos para a gestão da diversidade: a inclusão de deficientes intelectuais em uma federação pública do Brasil. RAM, Revista de Administração Mackenzie, São Paulo, v. 16, n. 2, p. 157-187, Apr. 2015. 
NASCIMENTO, L. C.; DAMASCENO, G. J. B.; ASSIS, L. J. Mercado de trabalho para as pessoas com deficiência em Betim/MG. In: Encontro Anual da Associação Nacional de PósGraduação e Pesquisa em Administração, 32., 2008, Rio de Janeiro. Anais eletrônicos... Rio de Janeiro: Enanpad, 2008.

NEPOMUCENO, M. F.; CARVALHO-FREITAS, M. N. As crenças e percepções dos gerentes e as possibilidades de trabalho das pessoas com deficiência. Psicologia em Pesquisa, v. 2, n. 1, p.81-94, 2008.

NEVES-SILVA, P.; PRAIS, F. G.; SILVEIRA, A. M. Inclusão de pessoas com deficiência no mercado de trabalho em Belo Horizonte, Brasil: cenário e perspectiva. Ciência \& Saúde Coletiva, Rio de Janeiro, v. 20, n. 8, p. 2549-2558, 2015.

ORGANIZAÇÃO INTERNACIONAL DO TRABALHO. Disability and work. https://www.ilo.org/global/topics/disability-and-work/WCMS_475650/lang--en/index.htm. Acesso em 30.07.2020.

PALACIOS, A. Functional Diversity, Bioethics and Sociological Theory: a New Approach to Disability. Intersticios. Revista sociológica de pensamiento crítico, v. 6, n. 1, p. 115-130, 2012.

PASSERINO, L. M.; PEREIRA, A. C. C. Educação, inclusão e trabalho: um debate necessário. Educação \& Realidade, Porto Alegre, v. 39, n. 3, p. 831-846, 2014.

PESSOTTI, I. P. Deficiência mental: da superstição à ciência. São Paulo: T. A.Queiroz Editores Ltda./EDUSP, 1984.

PETTIGREW, T. F. Generalized intergroup contact effects on prejudice. Personality and Social Psychology Bulletin, Sage, v. 23, n. 2, p. 173-185, 2007.

.; TROPP, L. R. A meta-analytic test of intergroup contact theory. Journal of Personality and Social Psychology, v. 90, n. 5, p. 751-783, 2006.

.; TROPP, L. R.; WAGNER, U.; CHRIST, O. Recent advances in intergroup contact theory. International Journal of Intercultural Relations, v. 35, n. 3, p. 271-280, 2011.

PICHON-RIVIÈRE, E. Teoria do vínculo. São Paulo: Martins Fontes, 1988

O processo grupal. São Paulo: Martins Fontes, 1988a.

RESENDE, M. G.; CARVALHO-FREITAS, M. N.; VIEIRA-SILVA, M. Crenças, Atitudes e Práticas dos Profissionais de Recursos Humanos Diante do Cumprimento da Lei de Cotas. Interação Psicol., Curitiba, v. 19, n.1, p. 47-59, jan./abr. 2015.

RIBEIRO, M. A.; CARNEIRO, R. A inclusão indesejada: as empresas brasileiras face à lei de cotas para pessoas com deficiência no mercado de trabalho. Organizações \& Sociedade, v. 16 , n. 50, art. 8, p. 545-564, 2009.

RODRÍGUEZ DÍAZ, S.; FERREIRA, M. A. V. Desde La dis-capacidad hacia La diversidad funcional. Um ejercicio de dis-normalización. Revista Internacional de Sociología, v. 68, n. 2, p. 289-309, 30 ago. 2010. 
RODARTE, M. P. F. Gestão de Recursos Humanos em pequenas empresas: políticas, práticas e desafios das organizações de pequeno porte na cidade de Belo Horizonte. 2012. Dissertação de Mestrado. Departamento de Ciências Administrativas. Universidade Federal de Minas Gerais. Belo Horizonte, Minas Gerais. 2012, 179 p.

RUDGE, A. M. Teoria do Vínculo. In V. L Giffoni; M. L. C. Gayoto; I. Domingues; M. I. S. Betiol. Grupo: Conceito e Processo. Mímeo. Rio de Janeiro, n.26, p. 98-113, 1992.

SEBRAE. As micro e pequenas empresas na exportação brasileira - Brasil e Estados, 2006. Disponível em: 〈http://www.sebrae.com.br/br/pesquisa_exportacao4/>

SEBRAE - DEPARTAMENTO INTERSINDICAL DE ESTATÍSTICA E ESTUDOS SOCIOECONÔMICOS - DIEESE. Anuário do trabalho na micro e pequena empresa: 2010-2011. Brasília, 2012.

SILVA, J. S.; PINTO, F. R. Conviver e Perceber a Deficiência: Relação e Influência nas Concepções de uma Amostra de Discentes de Administração. Gestão \& Regionalidade, v. 32, n. 96, p. 71-91, 2016.

SIMONELLI, A. P.; JACKSON FILHO, J. M. Análise da inclusão de pessoas com deficiência no trabalho após 25 anos da lei de cotas: uma revisão da literatura. Cad. Bras. Ter. Ocup., São Carlos, v. 25, n. 4, p. 855-867, 2017.

STONE-ROMERO, E. F.; STONE, D. L.; LUKASZEWSKI, K. The influence of disability on role-taking in organizations. In: KONRAD, A. M.; PRASAD, P.; PRINGLE, J. K. Handbook of workplace diversity. London: Sage, 2006. p. 401-430.

SUZANO, J. C. C., CARVAlHO-FREITAS, M. N.; TETTE, R. P. G., BRIGHENTI, C. R. G.; VIEIRA-SILVA, M. A Percepção dos Gestores Acerca do Desempenho de Trabalhadores com Diferentes Tipos de Deficiência. Interação em Psicologia, Curitiba, v. 18, n. 3, p. 239250, set./dez. 2014.

TANAKA, E. D. O; MANZINI, J. E. O que os empregadores pensam sobre o trabalho da pessoa com deficiência? Revista Brasileira de Educação Especial, v. 11, n. 2, p. 273-294, 2005.

THOMAS, D. A.; ELY, R. J. Making differences matter: a new paradigm for managing diversity. The Jossey-Bass reader on educational leadership, 197-210. San Francisco: JosseyBass, 1996.

TRIGUERO-SÁNCHEZ， R.; PEÑA-VINCES， J.; GUILLEN， J. Como melhorar o desempenho da empresa por meio da diversidade de colaboradores e da cultura organizacional. Revista Brasileira de Gestão de Negócios [online], v. 20, n. 3, 2018.

VEZZALI, L.; STATHI, S. Intergroup contact theory: recent developments and future directions. L. Vezzali; S. Stathi (Eds.) Current issues in social psychology. Routlege, v. 49, 2017. Retrieved from http://www.annualreviews.org/doi/10.1146/annurev.psych.49.1.65

VIOLANTE, R. R.; LEITE, L. P. A empregabilidade das pessoas com deficiência: uma análise da inclusão social no mercado de trabalho do município de Bauru, SP. Cadernos de Psicologia Social do Trabalho, São Paulo, v. 14, n. 1, p. 73-91, 2011. 
WERNKE, R.; PLETSCH, A. L. B.; JUNGES, I.; ZANIN, A. Características do financiamento do capital de giro de pequenas empresas do sul de Santa Catarina. REMIPE Revista de Micro e Pequenas Empresas e Empreendedorismo da Fatec Osasco, v. 3, n. 2, p. 211-242, 2017. 